\title{
Moringa protein drink increases testosterone and anabolic status of men with hyperlipidemia: A randomized controlled pilot study
}

\author{
Ciara Angeli. G. JUAN® \\ College of Human Kinetics, University of the Philippines, Diliman, Quezon City, Philippines.
}

\begin{abstract}
Testosterone is important in health, sexual function, body composition, and athletic performance. However, hormonal levels decrease with metabolic syndrome. Moringa oleifera, traditionally used as an aphrodisiac, has been shown to improve testosterone levels in metabolic syndrome. However, there is a dearth of studies on humans, and the mechanisms involved remain to be elucidated. This randomized, repeated measures study aims to determine if four-week supplementation of Moringa leaf powder in the form of a protein drink can improve resting levels of testosterone and related hormones, and whether any improvement translates to improved anabolic status during hypertrophy weight training. Relationships between hormonal levels and lipid profile were also explored. Three young men $(28.33 \pm 2.08)$ with hypercholesterolemia but normal testosterone levels were blood tested for hormonal levels and lipid profile at three time points: baseline, after Moringa supplementation, and after placebo supplementation. Pre-exercise and post-exercise testosterone and cortisol levels were measured on each testing day. Significant differences were found between Moringa and placebo in resting testosterone, anabolic status, and acute exercise-induced anabolic response. No significant difference was observed in any of the markers of lipid profile. Fourweek supplementation of Moringa leaf powder in the form of a protein drink significantly increased resting testosterone and anabolic status in men with hyperlipidemia but with normal testosterone levels. Men with hyperlipidemia showed blunted anabolic response to a hypertrophy weight training protocol, which was attenuated by Moringa supplementation. Mechanisms may be independent of improvements in lipid profile.
\end{abstract}

Keywords. Anabolic status, cortisol, exercise, moringa, testosterone, weight training.

\section{Introduction}

Testosterone is known to play a role in health, sexual function, and athletic performance. The coronavirus disease of 2019 (COVID-19) pandemic highlighted the possible role of testosterone in disease severity and mortality, with either very low or very high levels associated with poorer outcomes in men (Ghazizadeh et al., 2020; Mohamed et al., 2020; Wambier \& Goren, 2020). Suboptimal testosterone levels may predispose men to endothelial dysfunction, thrombosis, and impaired immune response (Gargaglioni \& Marques, 2020; Giagulli et al., 2020; Pozzilli \& Lenzi, 2020), as the hormone exerts antiinflammatory effects directly by inducing antiinflammatory cytokines and inhibiting proinflammatory ones, stimulating nitric oxide release, and modulating coagulative factors (Bianchi, 2018;
Giagulli et al., 2020). Indirectly, it helps reduce adipose tissue that secretes pro-inflammatory markers (Sattler et al., 2014), and potentiates insulin signaling (Rao et al., 2013) which is involved in innate immunity (Ieronymaki et al., 2019).

Testosterone also plays a key role in the metabolism of carbohydrate, protein, and fat. It controls gene expression of regulatory proteins involved in glycolysis, glycogenesis, and lipolysis (Kelly \& Jones, 2013). As the primary anabolic steroid, testosterone upregulates androgen receptor (AR) activity, protein synthesis, satellite cell activation, and other hormones involved in muscular hypertrophy, such as growth hormone and insulin-like growth factor 1 (Kraemer et al., 2020).

Studies on athletes also support the role of testosterone in athletic performance (Majumdar \& 
Srividhya, 2010), recovery (Kargarfard et al., 2018), fatigue (Bosco et al., 2000) and motivation (Crewther et al., 2016). Serum testosterone levels correlate negatively with VO2max and oxidative phosphorylation gene expression (Pitteloud et al., 2005). A low testosterone-cortisol ratio (T/C) is usually indicative of overtraining and catabolic status, while a high $\mathrm{T} / \mathrm{C}$ is associated with improved performance and anabolic status (Majumdar \& Srividhya, 2010).

Unfortunately, total testosterone levels decrease in men with metabolic syndrome (Gleicher et al., 2020). Such decrease may be caused by defective cholesterol transport (Culty et al., 2002), increased insulin resistance, sex hormone binding globulin (SHBG), and leptin levels on Leydig cells, as well as reduced gonadotropin secretion mediated by chronic, lowgrade inflammation and increased oxidative stress (Pivonello et al., 2019).

Given the role of testosterone in health and athletic performance, it is imperative to develop safe and preventive interventions in optimizing hormonal levels that would appeal to men. Moringa, a native vegetable traditionally used as an aphrodisiac, has been shown in animal studies to increase testosterone levels (Mohamed et al., 2019; Ogunsola et al., 2017; Prabsattroo et al., 2015; Suarni et al., 2019; Syarifuddin et al., 2017). If Moringa also improves testosterone levels in humans, supplementation in the form of a palatable drink that mimics whey protein supplements may be acceptable to men, who tend to have less favorable attitudes and perceived behavior control than women regarding eating vegetables (Emanuel et al., 2012).

Dietary consumption of Moringa is encouraged by several health organizations due to the plant's nutrient content and potential in treating various diseases. It has been shown to have antioxidant, antiinflammatory, cholesterol-lowering, antidiabetic, and hepatoprotective properties (Alegbeleye, 2018; Gupta et al., 2012; Mbikay et al., 2012; Waterman et al., 2015; Vargas-Sánchez et al., 2019). Its traditional use in Ayurvedic medicine as an aphrodisiac is supported by animal studies (Goswami et al., 2016; Suarni et al., 2019; Syarifuddin et al., 2017; Zade et al., 2013).

In rats, four-week supplementation of Moringa leaf extract at $200-500 \mathrm{mg} / \mathrm{kg}$ body weight per day increased serum testosterone, luteinizing hormone (LH), follicle stimulating hormone, steroidogenic acute regulatory (StAR) protein expression, and insulin levels (Mohamed et al., 2019; Ogunsola et al., 2017). A shorter seven-day supplementation period of the same extract at $250 \mathrm{mg} / \mathrm{kg}$ body weight per day also increased testosterone and Leydig cell count in rats (Prabsattroo et al., 2015).

There is also emerging evidence that Moringa supplementation increases testosterone levels in men with hyperlipidemia. Three-month supplementation of Moringa leaf powder at $500 \mathrm{mg}$ twice a day increased serum testosterone, with concurrent reductions in cholesterol levels in men (Munawar et al., 2019).

Similarly, 50-day supplementation of Moringa leaf powder at $4.6 \mathrm{~g}$ per day also decreased total cholesterol and increased HDL (Nambiar et al., 2010), while 40-day supplementation at $8 \mathrm{~g}$ per day decreased total cholesterol, triglycerides, and LDL in men (Kumari, 2010).

\section{Mechanisms of Action}

Improvements in lipid profile observed in Moringa leaf supplementation studies are attributed to various compounds, including insulin-like plant proteins (Paula et al., 2017) and flavonols like quercetin (Vargas-Sánchez et al., 2019) and kaempferol (Lako et al., 2007) that have antidiabetic, anti-obesity, and anti-inflammatory effects (Chen, S. et al. (2016).

Quercetin and kaempferol have been shown to increase glucose uptake, GLUT-4 translocation, GLUT-4 protein content, and AMPK phosphorylation in skeletal muscle (Eid et al., 2015; Han et al., 2017). Chlorogenic acid, also found in Moringa, likewise triggers AMPK activity (Ong et al., 2013) and improves glucose and lipid metabolism in metabolic syndrome (Karthikesan et al., 2010).

Activation of AMPK in the skeletal muscle triggers key metabolic processes, including increased ATP generation, lipolysis, and beta oxidation, as well as inhibition of lipogenesis and cholesterol biosynthesis (Lopes et al., 2017; Motoshima et al., 2006). Modulation of AMPK activity, either pharmacologically or genetically, affects hormoneinduced StAR protein expression and steroidogenesis (Abdou et al., 2014).

In animal studies, high dietary cholesterol reduces resting testosterone levels by down-regulating StAR and other steroidogenic enzymes and activating endoplasmic reticulum stress (Yu et al., 2019), reducing testicular $\mathrm{LH}$ and human chorionic gonadotropin binding (Tanaka et al., 2001), and impairing the testicular renin-angiotensin system (Martínez-Martos et al., 2011). 
Improvements in lipid profile after Moringa supplementation are likely due to decreased reactive oxygen species (ROS) (Das et al., 2015), decreased rate of lipolysis and conversion of free fatty acids to phospholipids and cholesterol in the liver (Olayaki et al., 2015), and increased LDL receptors (Fuhrman, \& Aviram, 2001).

Such increase in LDL receptors affects both testosterone and cortisol production, as all steroid hormones are derived from cholesterol (Eacker et al., 2008), and steroidogenic cells take up circulating LDL for hormone synthesis (Miller \& Bose, 2011). When intracellular cholesterol concentrations are high, LDL receptor activity is downregulated, thereby decreasing cholesterol uptake, synthesis, and deesterification (Miller \& Bose, 2011). Both increased triglycerides and insulin resistance inhibit the hypothalamic-pituitary-gonadal (HPG) axis (Kelly \& Jones, 2013; Muraleedharan \& Jones, 2010).

Moringa is also a significant source of zinc (Gopalakrishnan et al., 2016), which acts as an antioxidant in the Leydig cells that produce testosterone (Fallah et al., 2018). Zinc deficiency impairs angiotensin-converting enzyme activity, which leads to depletion of testosterone (Bedwal \& Bahuguna, 1994).

Testosterone synthesis depends on the adequacy of zinc in the diet (Biswajit et al., 2013), and zinc supplementation improves serum testosterone levels in a dose-dependent manner (Biswajit et al., 2013; Kumar et al., 2006). In one study, Moringa leaf supplementation was comparable to zinc supplementation in increasing libido (Syarifuddin et al., 2016).

Improvements in LH levels observed in Moringa supplementations studies is also attributed to zinc. LH increase may also be a separate mechanism driving testosterone production, as LH stimulates the activity of LDL receptors and uptake of LDL cholesterol (Miller \& Bose, 2011). Zinc supplementation at $250 \mathrm{mg} /$ day for 6 weeks improved both $\mathrm{LH}$ and testosterone levels in men (Jalali et al., 2010).

Another possible mechanism by which Moringa may increase testosterone levels is through Vitamin E, which has been shown to reduce testicular oxidative stress and increase Leydig cell steroidogenesis in diabetes (Aybek et al., 2008). Moringa leaves are a good source of Vitamin E, with six times more levels than in rapeseed oil (Ganatra et al., 2012), and in concentrations similar to those found in nuts (Efiong et al., 2013). In healthy men, three-week administration of at least $257 \mathrm{mg} / \mathrm{kg}$ of body weight per day of Vitamin $\mathrm{E}$ in the form of extra virgin olive oil and argan oil significantly increased TT levels (Derouiche et al., 2013).

The synergistic effects of trace elements, particularly zinc, as well as flavonols and polyphenols in Moringa may be the main mechanisms for improving testosterone levels. Testosterone, in turn, differentially regulates targets of lipid and glucose metabolism in the muscle, liver, and adipose tissue (Kelly et al., 2016). There is a positive relationship between TT and insulin sensitivity in men independent of SHBG levels (Pitteloud et al., 2005). Furthermore, there is a positive correlation between TT and HDL, and an inverse correlation between TT and either triglycerides or total cholesterol (Thirumalai et al., 2015).

Testosterone, cortisol, and anabolic status during weight training. The potential testosteroneenhancing effects of Moringa may translate to improved anabolic response (T/C) during weight training via increased resting levels of testosterone or decreased cortisol and related inflammatory markers.

Testosterone and cortisol exert opposing effects, compete for glucocorticoid-binding sites (Hackney \& Walz, 2013), and vary inversely during exercise (Brownlee et al., 2005). Moderate to high-intensity ( $80 \%$ of $1 \mathrm{RM}, 120 \mathrm{~s}$ rest period), high-volume resistance training acutely induces high levels of testosterone in young men (Crewther et al., 2008; Juan, 2019), but also high cortisol in men with metabolic disorders (Gar et al., 2020; Wong \& Harber, 2006). There is evidence that cortisol may be a more important determinant of anabolic status than testosterone (Ratamess et al., 2005).

Dietary cholesterol also induces inflammatory cytokines (Zhao et al., 2017) that interfere with metabolic response during exercise (Febbraio et al., 2004; Proschinger et al., 2019; Vargas et al., 2014). Inflammatory cytokines also induce cortisol directly and indirectly (Bethin et al., 2000; Steensberg et al., 2003) creating a vicious cycle of dysregulated hormonal response.

This paper aims to determine whether four-week supplementation of Moringa leaf powder can improve both resting and exercise-induced TT and $\mathrm{T} / \mathrm{C}$, possibly through increased testosterone production or improved metabolic and inflammatory profile. 


\section{Methods}

\section{Research Design}

This is a preliminary randomized controlled study utilizing a single-blind, repeated measures design. All participants underwent four-week supplementation with Moringa drink, and another four-week supplementation with placebo drink. The treatment periods were counterbalanced for each participant and separated by at least two weeks of washout period, similar to previous studies on zinc (Riggio et al., 1991), quercetin (Xiao et al., 2014), and Vitamin E (Belcher et al., 1993) supplementation on humans. Participants were instructed to maintain their normal diet and physical activity throughout the study.

Blood tests for sex hormones (LH, TT), lipid profile (cholesterol, triglycerides, LDL), and exercise hormones (cortisol, T/C) before and after weight training were done in three time points: baseline, after supplementation with Moringa drink, and after administration of placebo drink.

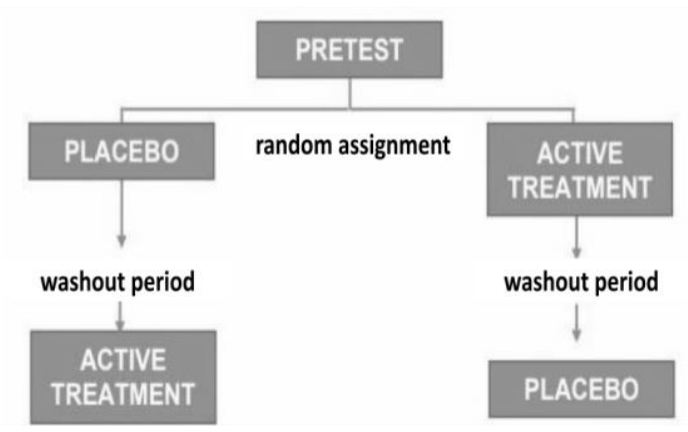

Figure 1. Research design.

\section{Participants}

Participants were screened based on factors known to affect testosterone and cortisol levels, namely: age (Feldman et al., 2002), relationship status (Van Anders et al., 2006; Farrelly et al., 2015; Mendoza et al., 2000), physical activity (Vaamonde et al., 2012), training status (Coffey et al., 2006), use of anabolic steroids (Rasmussen et al., 2016), smoking (Wang et al., 2013), alcohol consumption (Sarkola et al., 2003), sleep patterns (Leproult et al., 2011), and diet (Allen et al., 2000).

All were young men (age $28.33 \pm 2.08$ ), omnivores, moderately and recreationally trained in weightlifting, in long-term committed relationships, and without any history of anabolic steroid use. They were non-smokers, not heavy drinkers, and not chronically sleep-deprived. They had similar physical activity levels and access to training facilities being members of the same fitness gym.

All had baseline cholesterol levels exceeding the normal range of $200 \mathrm{mg} / \mathrm{dL}$. However, TT and LH were within the normal range of 270-1070 ng/dL and 1.24-7.8 $\mathrm{mIU} / \mathrm{mL}$, respectively. Baseline characteristics of participants are summarized in Table 3.

\section{Table 1}

Baseline characteristics of participants in means and standard deviation (in parentheses).

\begin{tabular}{lc}
\hline Variables & Mean \pm SD \\
\hline Age (years) & $28.33 \pm 2.08$ \\
Weight (kg) & $87.87 \pm 2.22$ \\
Height (cm) & $174.41 \pm 7.76$ \\
BMI (kg/m²) & $28.97 \pm 1.91$ \\
Total cholesterol (mg/dl) & $224.45 \pm 29.99$ \\
Triglycerides (mg/dl) & $156.06 \pm 61.44$ \\
LDL (mg/dl) & $145.88 \pm 31.59$ \\
Total testosterone (ng/dl) & $484 \pm 61.14$ \\
$\begin{array}{l}\text { Exercise-induced testosterone } \\
\text { (ng/dl) }\end{array}$ & $445.1 \pm 102.93$ \\
Luteinizing hormone (miu/ml) & $5.82 \pm 0.74$ \\
Cortisol (ug/dl) & $9.40 \pm 2.71$ \\
Exercise-induced cortisol (ug/dl) & $11.90 \pm 6.18$ \\
$\begin{array}{l}\text { Weight training frequency, days } \\
\text { per week }\end{array}$ & $4.67 \pm 0.58$ \\
$\begin{array}{l}\text { Weight training history, years since } \\
\text { started }\end{array}$ & $9.0 \pm 1.0$ \\
$\begin{array}{l}\text { Smoking frequency, sticks per } \\
\text { week }\end{array}$ & $0 \pm 0$ \\
Alcohol use, servings per week & $0.33 \pm 0.58$ \\
\hline
\end{tabular}

\section{Recruitment}

This study made use of a non-probability, voluntary convenience sampling design. Convenience sampling was chosen as the study was started during government-imposed community quarantine when 
gym access was limited to the public. A call for participation was announced through social media. Interested participants signed an institutionally approved informed consent form and were screened for the inclusion/exclusion criteria.

Four participants who met the inclusion criteria gave their consent to join the study. However, one participant tested positive for COVID-19 and had to be excluded. The remaining three finished all three testing periods. An a priori power analysis using $\mathrm{G}^{*}$ Power program yielded $60-70 \%$ chance of correctly rejecting the null hypothesis with the current repeated measures design.

\section{Interventions}

Each participant was given one $350 \mathrm{ml}$ bottle of Moringa drink or its placebo counterpart per day for a span of four weeks. The Moringa drink contained 10 $\mathrm{g}$ of Moringa leaf powder as the active ingredient, while the placebo drink contained food coloring. Both drinks contained soy milk, banana, and artificial matcha flavor.

Daily supplementation of Moringa leaf powder in the form of food products ranges from 10-30 g (Idohou-Dossou et al., 2011; Barichella et al., 2018; Glover-Amengor et al., 2017; Tshingani et al., 2017). The amount of $10 \mathrm{~g}$ was chosen based on a previous study among men with hyperlipidemia (Munawar et al., 2019) and a taste test conducted with the current participants.

Ingredients were chosen to mimic the texture and taste of whey protein that men would normally drink for muscle gain. Participants described the taste as "creamy matcha flavor" that resembles milk tea. The ingredients, other than the Moringa powder, were not a significant source of quercetin, Vitamin E, and zinc. Short-term soymilk consumption for up to 12 weeks at $400 \mathrm{ml}$ daily does not affect resting testosterone levels in men (Nagata et al., 2001).

The drinks were prepared and delivered to each participant every week for a period of four weeks. Participants were instructed to store the drinks in the freezer upon receipt to ensure freshness and palatability.

\section{Procedures}

\section{Pretest}

This study was approved by the University of the
Philippines Manila Research Ethics Board (2020530-01) and was conducted in compliance with the principles enunciated in the Helsinki Declaration. Each participant accomplished an institutionally approved informed consent form and lifestyle questionnaire and underwent submaximal strength test and exercise familiarization at the gym. A taste test was also conducted to ensure acceptability and palatability of the Moringa and placebo drinks. Participants were not informed about the composition of the drinks and were asked to refrain from vigorous physical activity, alcohol, caffeine, and ergogenic supplements at least $48 \mathrm{~h}$ from testing.

\section{Blood Tests}

After at least $48 \mathrm{~h}$ from pretest, each participant reported to the gym at $10 \mathrm{AM}$ after 10-12 hours of overnight fast. Blood samples were immediately collected from the right antecubital fossa while the participant was seated. After the first blood extraction, the participant was given a standard breakfast of chicken and rice, which was kept constant in every testing day. The participant rested for $2 \mathrm{~h}$ before starting the exercise protocol.

In every testing day, blood samples were collected twice: At a fasted state to determine baseline levels of resting TT, resting cortisol, and lipid profile, and immediately after exercise to determine exerciseinduced TT and cortisol. Whole blood was centrifuged (Hsiangtai, Taiwan) for 10 minutes, after which serum was aspirated, aliquoted, and analyzed (Cobas E 411, Roche Diagnostics, USA). Samples were stored in the medical clinic's laboratory for one week to allow for analysis of other markers that may help explain results, after which they were disposed of properly according to professional standards. Blood test procedures were kept constant in every testing day by ensuring that participants reported to the gym at $10 \mathrm{AM}$, and that the same medical technologist collected the samples throughout the study.

\section{Exercise Protocol}

The exercise protocol involved two compound leg exercises (Smith machine barbell back squat and supine leg press), each performed for five sets of 10RM $(75 \% 1 \mathrm{RM})$ with 2 -minute rest periods between sets. Each participant performed a standard warm-up consisting of five minutes of leg mobility drills followed by two submaximal sets on the leg press machine (20 repetitions, 50\% 1RM) before starting the first set of the hypertrophy protocol. 
When the participant felt fatigued and unable to maintain $75 \% 1 \mathrm{RM}$ for 10 repetitions, the load was reduced to ensure five sets of 10 repetitions could still be completed. The entire protocol, including warmup, lasted for approximately 30 minutes.

\section{Statistical Analyses}

The null hypothesis that there is no significant difference between placebo and Moringa treatment in terms of resting and exercise-induced levels of hormones and lipid profile after four-week supplementation was tested using univariate analysis of covariance (ANCOVA) controlling for bodyweight changes in the participants. Withinsubject changes in exercise-induced hormonal response was tested using repeated measures ANCOVA. Bivariate correlation was also used to explore relationships among variables.

All continuous variables were tested for normality using Shapiro-Wilk test and for equality of variances using Levene's test. Non-normal variables were transformed using the log transform function in Statistical Package for the Social Sciences (SPSS) Version 27 software. Data are presented as mean \pm standard deviation. For all statistical analyses, $p<.05$ was considered statistically significant.

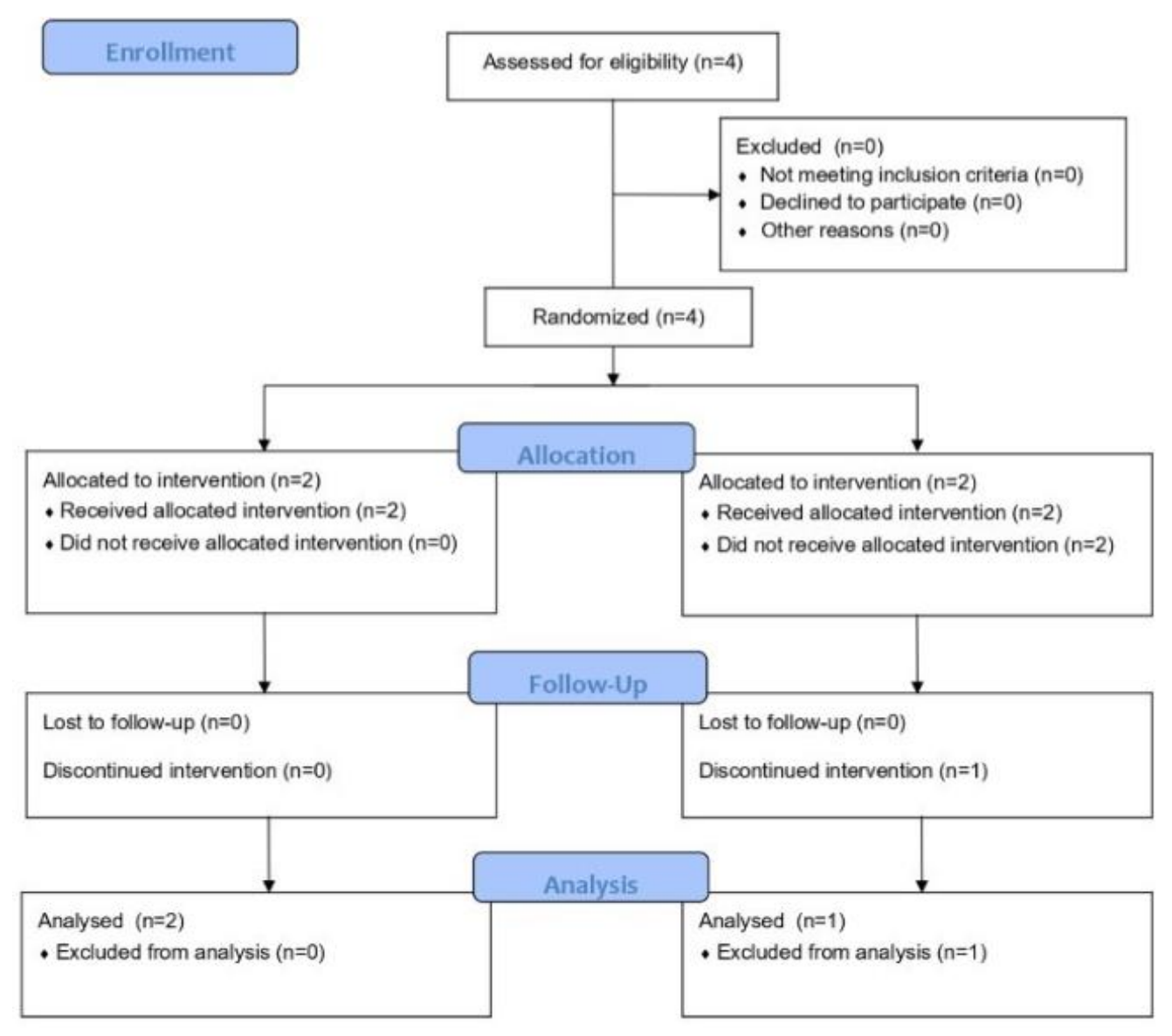

Figure 2. Flow chart of the study design.

\section{Results}

\section{Between Group Differences}

Assumptions of normality and equality of variances were established for all continuous variables. Univariate ANCOVA showed a statistically significant difference between Moringa and placebo $(p=.02)$, and between Moringa and baseline $(p=.02)$ in resting testosterone levels when controlling for changes in bodyweight.

A comparison of estimated marginal means revealed the Moringa group had $12.1 \%$ increase in resting testosterone from baseline, while the placebo group had .66\% increase from baseline. 
Both treatment group and bodyweight significantly affected resting testosterone at $F(2,5)=7.77, p=$ $0.03, \eta^{2}=.76$ and $F(1,5)=67.79, p<0.001, \eta^{2}=.93$, respectively. Hence, the research hypothesis that Moringa is better than placebo in increasing resting testosterone levels is confirmed, with $76 \%$ of the total variance influenced by treatment group.

There was also a statistically significant difference between Moringa and placebo $(p=.01)$ in resting anabolic status (T/C) when controlling for changes in bodyweight. A comparison of estimated marginal means revealed the Moringa group had 19.61\% increase in resting anabolic status from baseline, while the placebo group had $27.45 \%$ decrease in resting anabolic status from baseline.
Both treatment group and bodyweight significantly affected resting anabolic status at $F(2,5)=11.16$, $p=.01, \eta^{2}=.82$ and $F(1,5)=75.73, p<.001, \eta^{2}=.94$, respectively. Hence, the research hypothesis that Moringa is better than placebo in increasing resting anabolic status is confirmed, with $82 \%$ of the total variance influenced by treatment group.

No significant between-group differences were found for resting cortisol, LH, and lipid profile. Thus, improvements in resting testosterone and anabolic status may be independent of improvements in lipid profile or decreased cortisol at rest.

Table 2

Changes in pretest-posttest scores from baseline by treatment group.

\begin{tabular}{lccccc}
\hline Variables & Baseline & Placebo & Change & Moringa & Change \\
\hline Resting testosterone (ng/dl) & $484 \pm 61.14$ & $483.7 \pm 23.41$ & -0.3 & $507.19 \pm 95.25$ & 23.19 \\
Exercise testosterone (ng/dl) & $445.1 \pm 102.9$ & $500.93 \pm 23.48$ & 55.87 & $462.6 \pm 53.38$ & 17.53 \\
Resting cortisol (ug/dl) & $9.40 \pm 2.71$ & $12.23 \pm 1.11$ & 2.83 & $11.11 \pm 4.6$ & 1.72 \\
Exercise cortisol (ug/dl) & $11.90 \pm 6.18$ & $15.09 \pm 2.84$ & 3.19 & $13.81 \pm 7.61$ & 1.91 \\
Resting T/C & $0.06 \pm 0.02$ & $0.04 \pm 0.01$ & -0.02 & $0.05 \pm 0.03$ & -0.00 \\
Exercise T/C & $0.04 \pm 0.01$ & $0.03 \pm 0.01$ & -0.01 & $0.04 \pm 0.04$ & -0.00 \\
LH (miu/ml) & $5.82 \pm 0.74$ & $4.11 \pm 1.6$ & -1.72 & $5.47 \pm 0.49$ & -0.35 \\
Cholesterol (mg/dl) & $224.45 \pm 29.99$ & $223.55 \pm 19.38$ & -0.90 & $214.28 \pm 21.11$ & -10.17 \\
Triglycerides (mg/dl) & $156.06 \pm 61.44$ & $166.68 \pm 78.33$ & 10.62 & $142.19 \pm 43.20$ & -13.86 \\
LDL (mg/dl) & $145.88 \pm 31.59$ & $145.94 \pm 8.26$ & 0.06 & $139 \pm 27.12$ & -6.88 \\
\hline
\end{tabular}

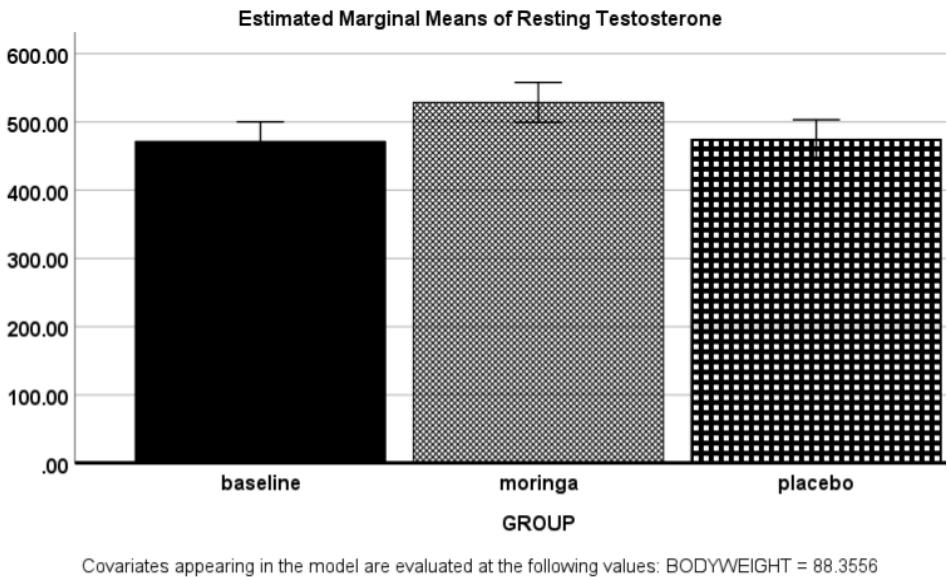

Error bars: $95 \% \mathrm{Cl}$

Figure 3. Estimated marginal means of resting testosterone (ng/dl) with statistically significant differences between treatment groups. 


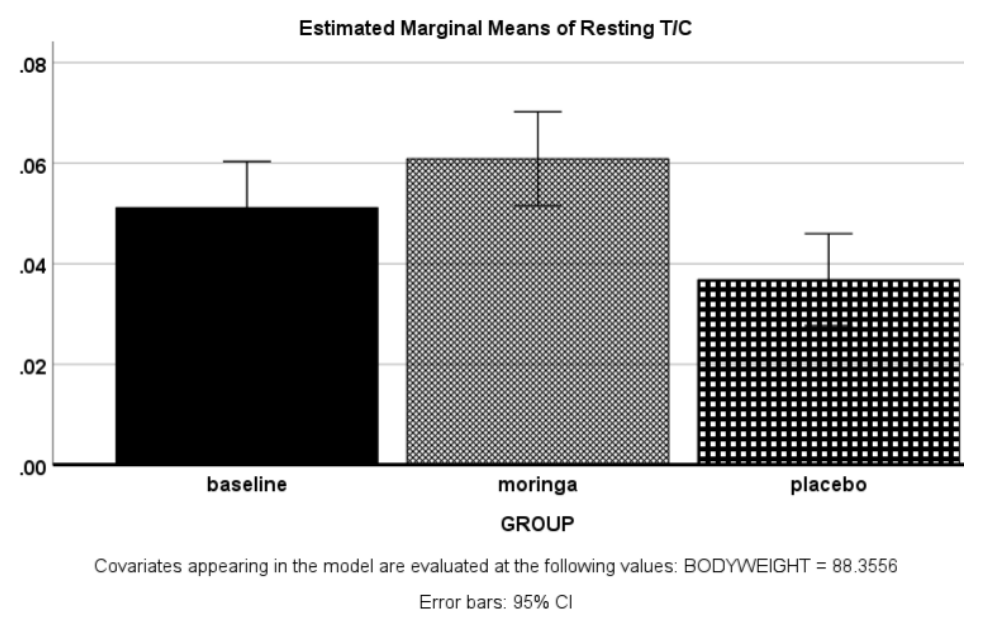

Figure 4. Estimated marginal means of resting anabolic status (T/C) with statistically significant differences between treatment groups.

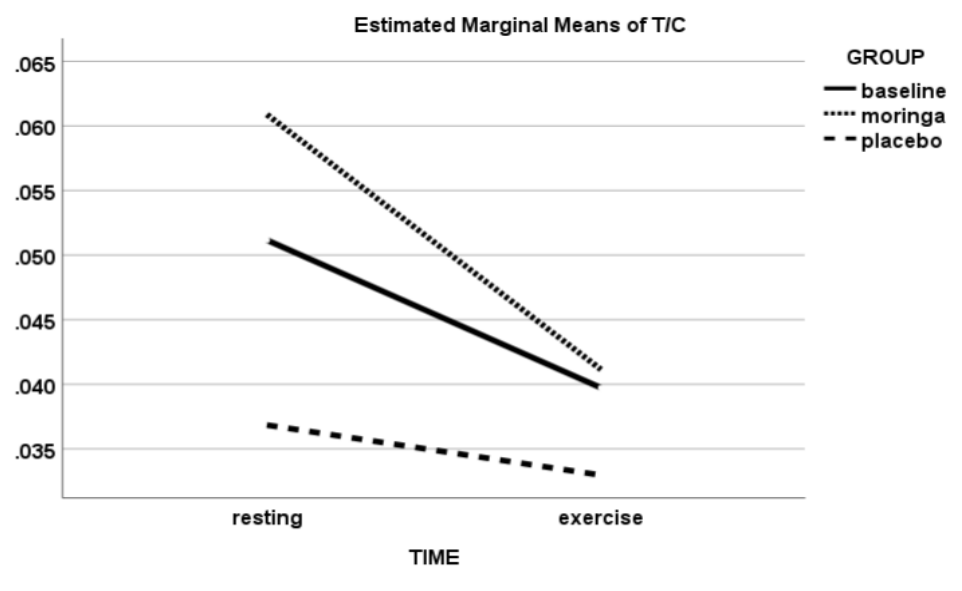

Figure 5. Exercise-induced anabolic response (T/C) showing significant differences between groups, with Moringa treatment resulting in significantly stronger exercise-induced response compared to placebo.

\section{Within-Subject Trends in Acute Hormonal Response}

Repeated measures ANCOVA did not yield any statistically significant acute change in testosterone levels from resting to exercise. There was also a marginally statistically significant trend towards increased acute cortisol response to weight training in all groups.

However, there was a statistically significant acute decrease in anabolic response (T/C) to weight training $\left(F(1,5)=15.65, p=.01, \eta^{2}=.76\right)$. Pairwise comparison showed a significantly stronger magnitude of exercise-induced response in Moringa compared to placebo $(p=.03)$.

\section{Discussion}

\section{Moringa Increases Testosterone Production Possibly via Decreased Inflammation}

The paucity of mechanistic studies on Moringa supplementation in metabolic syndrome limits the discussion of current results to related disorders. In one study on rats with diet-induced hyperinsulinemia, Moringa supplementation increased testosterone with concurrent improvements in testicular markers of androgen biosynthesis (StAR protein and 3 $\beta$-hydroxysteroid dehydrogenase expression), and decrease in lipid peroxidation in the liver, possibly through decreased ROS (Mohamed et al., 2019). The ROS-scavenging 
effects of Moringa was previously established in rats with high fat diet-induced oxidative stress (Das et al., 2015). Increased ROS inhibits StAR protein expression and its cholesterol transfer activities necessary for steroidogenesis (Diemer et al., 2003).

Hypercholesterolemia also increases ROS (Abdelhalim et al., 2012; Csonka et al., 2016) and reduces testosterone by down-regulating StAR protein and other steroidogenic enzymes and activating endoplasmic reticulum stress (Yu et al., 2019), reducing LH and human chorionic gonadotropin binding (Tanaka et al., 2001), and impairing the testicular renin-angiotensin system (Martínez-Martos et al., 2011).

In the current study, however, the moderately hyperlipidemic participants had normal baseline levels of resting testosterone, which was still improved after Moringa supplementation, suggesting that even non-hypogonadal men may benefit from its antioxidant effects.

\section{Men with Hyperlipidemia Have Blunted Testosterone Response to Weight Training}

Another key insight in the current study is the blunted acute exercise-induced hormonal response of men with hypercholesterolemia. Previous studies using the same exercise protocol recorded increased acute testosterone response in the same age group of healthy men (Crewther et al., 2008; Juan, 2019), which was not observed in the current study. There was also a marginally significant trend towards increased exercise-induced cortisol in all treatment groups. There were, however, significant negative correlations between exercise-induced anabolic response and LDL ( $r=-.73, p=.025)$, and between resting anabolic status and exercise-induced testosterone response $(r=-.86, p=.025)$.

Taken together, these trends show a dysregulated exercise-induced hormonal response in men with moderate hyperlipidemia, where blunted exerciseinduced testosterone response is accompanied by increased cortisol response, and with higher hormonal levels at rest associated with lower levels during exercise.

\section{Moringa Supplementation May Attenuate Blunted Hormonal Response to Exercise}

The dearth of studies on factors affecting exerciseinduced hormonal response also limits the current discussion to related hormones and inflammatory markers. People with metabolic disorders have been shown to have blunted exercise-induced growth hormone response (Wong et al., 2006) and exaggerated cortisol response (Gar et al., 2020) to exercise. Testosterone and cortisol exert opposing effects, compete for glucocorticoid-binding sites (Hackney \& Walz, 2013), and vary inversely during exercise (Brownlee et al., 2005). There is evidence that cortisol may be a more important determinant of anabolic status than testosterone (Ratamess et al., 2005).

Thus, the greater magnitude of exercise-induced anabolic response after Moringa supplementation, although downward in direction, may represent an attenuation of previously blunted hormonal response in the participants with moderate hyperlipidemia. Furthermore, improved testosterone levels and anabolic status at rest did not translate to increased, but rather resulted in decreased yet stronger anabolic response during weight training, possibly due to a combination of blunted testosterone and increased cortisol levels during exercise.

Possible explanations for the blunted and decreased anabolic response of the current participants to a normally anabolic weight training include cholesterol-induced inflammation and endothelial dysfunction. Dietary cholesterol increases inflammatory cytokines (Zhao et al., 2017) that interfere with metabolic response during exercise (Febbraio et al., 2004; Proschinger et al., 2019; Vargas et al., 2014). Inflammatory cytokines also induce cortisol directly and indirectly (Bethin et al., 2000; Steensberg et al., 2003). Cholesterol-induced endothelial dysfunction (Hermida et al., 2013) may also result in decreased blood flow during highintensity lower body exercise that relies greatly on endothelial nitric oxide production (Green et al., 2004).

\section{Increased Resting Testosterone Precedes Improvements in Lipid Profile}

Another unexpected finding of the current study is the lack of significant improvement in any of the variables for lipid profile (cholesterol, triglycerides, LDL). Such lack of improvement may be attributed to the length of treatment period. Four-week supplementation may not have been enough to create the significant improvements in lipid profile observed by previous studies, which used 40 days to 12 weeks supplementation period (Kumari, 2010; Munawar et al., 2019; Nambiar et al., 2010). Improvements in lipid profile may normalize the 
acute exercise-induced hormonal response of the participants and determine whether Moringa supplementation also improves such response.

Similarly, the lack of between-group differences in LH and the downward trend of LH levels from baseline to Moringa and placebo, respectively (see Table 4), may be attributed to hyperlipidemia. There is a positive correlation between serum total cholesterol and LH in subjects with hypercholesterolemia (Yang et al., 2016). The initially high baseline levels of LH observed in this study may have been attenuated by supplementation, leading to lower circulating levels in both treatment groups.

Furthermore, the significant increase in resting testosterone in the Moringa group may have resulted in decreased LH via negative feedback mechanism in the HPG axis (Roelfsema et al., 2018). In the current study, however, LH was not significantly correlated with any of the variables.

\section{Generalizability}

This preliminary study aimed to determine whether four-week supplementation of Moringa leaf powder can improve both resting and exercise-induced testosterone and anabolic status, possibly through increased testosterone production or improved lipid profile. Although experimental in design, the small sample size limits the generalizability of the current study.

\section{Limitations}

The inevitable behavioral changes brought by the pandemic may have resulted in additional confounding factors that may have affected hormonal responses. The current study only accounted for changes in bodyweight of the participants throughout the three testing periods. Changes in physical activity affects testosterone levels more than other lifestyle factors (Kumagai et al., 2016). Although the participants were instructed to maintain their normal physical activity levels throughout the study, government restrictions on outdoor activities during pandemic may have affected activity levels.

\section{Conclusion}

The hypothesis that four-week supplementation of Moringa powder has a statistically significant effect on resting and exercise-induced hormonal levels of non-hypogonadal men with moderate hyperlipidemia was confirmed in terms of resting testosterone and exercise-induced anabolic response. Such effect preceded improvements in lipid profile, suggesting that increased testosterone production through antioxidants, not improvement in lipid profile, may be the primary mechanism for increased resting testosterone levels in Moringa supplementation studies. Furthermore, to achieve improvements in hormonal response during exercise, antioxidant mechanisms leading to improved endothelial function and inflammatory profile may be involved.

\section{Applications}

To the author's knowledge, this is the first Moringa supplementation study on humans to show improved testosterone levels in non-hypogonadal men even without improvements in metabolic profile, extending its use as a potential ergogenic aid. At least $10 \mathrm{~g}$ of Moringa leaf powder, when taken daily for at least four weeks, may improve resting testosterone levels in men with moderate hyperlipidemia but normal testosterone levels. The amount of $10 \mathrm{~g}$ had no recorded side effects and was considered palatable when mixed with other flavors. However, four-week supplementation using the same dosage may not be enough if the goal is to improve lipid profile.

Such improvement in resting testosterone, even without concurrent improvement in metabolic profile, may also be useful in restoring decreased testosterone levels as a side effect of common pharmacological therapies for metabolic syndrome such as statins (Stanworth et al., 2009). In one study, depleted levels of testosterone induced by statins was restored by Moringa supplementation (Munawar et al., 2019).

This is also the first study to explore the effects of hyperlipidemia on exercise-induced anabolic response. The current study showed that even moderate hypercholesterolemia blunted the acute anabolic response to a hypertrophy training protocol, which was attenuated by Moringa supplementation.

Such anabolic hormone response during weight training is important as acute increases in anabolic hormones during exercise mediate desired training adaptations such as increased muscle cross sectional area (Bosco et al., 2000) and strength (Ahtiainen et al., 2003). 


\section{Recommendations}

Future studies should measure antioxidants and inflammatory markers together with testosterone levels to further elucidate mechanisms. Measurements should be done in both short-term (less than $4 \mathrm{w}$ ) and long-term (more than $4 \mathrm{w}$ ) supplementation periods to track possible changes in the said biomarkers and determine the minimum supplementation period required for desired effects. Different populations (non-hyperlipidemic, nonhypogonadal) of men should be tested to confirm if the testosterone-enhancing effects of Moringa also apply to healthy samples.

\section{Acknowledgment}

The author would like to thank the participants who volunteered despite the pandemic.

\section{Conflict of Interest}

This study was self-funded for the author's master's thesis. She declares no conflict of interest.

\section{References}

Abdelhalim, M. \& Abdelhalim, K. (2010). The potential influence of high cholesterol diet-induced oxidative stress on composition and properties of red blood cells in rabbits. Afr J Microbiol Res, 4, 836-843.

Ahtiainen, J.P., Pakarinen, A., Alen, M., Kraemer, \& W.J., Häkkinen, K. (2003). Muscle hypertrophy, hormonal adaptations and strength development during strength training in strength-trained and untrained men. Eur J Appl Physiol, 89(6), 555-63.

Alegbeleye, 0.0. (2018). How functional is moringa oleifera? A review of its nutritive, medicinal, and socioeconomic potential. Food Nutr Bull, 39(1), 149170.

Allen, N.E., Appleby, P.N., Davey, G.K., Key, T.J. (2000). Hormones and diet: Low insulin-like growth factor-I but normal bioavailable androgens in vegan men. $\mathrm{Br} \mathrm{J}$ Cancer, 83(1), 95-97.

Anthanont, P., Lumlerdkij, N., Akarasereenont, P., Vannasaeng, S., Sriwijitkamol, A. (2016). Moringa Oleifera Leaf Increases Insulin Secretion after Single Dose Administration: A Preliminary Study in Healthy Subjects. J Med Assoc Thai, 99(3), 308-313.

Antinozzi, C., Marampon, F., Corinaldesi, C., Vicini, E., Sgrò, P., Vannelli, G.B., Lenzi, A., Crescioli, C., \& Di Luigi, L. (2017). Testosterone insulin-like effects: an in vitro study on the short-term metabolic effects of testosterone in human skeletal muscle cells. J Endocrinol Invest, 40(10), 1133-1143.

Armstrong, L.E., Casa, D.J., Millard-Stafford, M.L., Morán, D.S., Pyne, S.W., \& Roberts,W.O. (2007). American College of Sports Medicine Position Stand: Exertional heat illness during training and competition. Med Sci Sports Exerc, 39 (3), 556-72.

Aybek, H., Aybek, Z., Rota, S., Şen, N., \& Akbulut, M. (2008). The effects of diabetes mellitus, age, and vitamin $\mathrm{E}$ on testicular oxidative stress. Fertility \& Sterility, 90(3), 755-760.

Barichella, M., Pezzoli, G., Faierman, S.A., Raspini, B., Rimoldi, M., Cassani, E., Bertoli, S., Battezzati, A., Leone, A., Iorio, L., Ferri, V., Pinelli, G., Pusani, C., Bolliri, C., Cilia, R., Caronni, S., De Marco, P., \& Cereda E. (219). Nutritional characterisation of Zambian Moringa oleifera: acceptability and safety of short-term daily supplementation in a group of malnourished girls. Int $J$ Food Sci Nutr, 70(1), 107-115.

Bedwal, R.S., \& Bahuguna, A. (1994). Zinc, copper and selenium in reproduction. Experientia, 50(7), 626-640.

Belcher, J.D., Balla, J., Balla, G., Jacobs, D.R. Jr, Gross, M., Jacob, H.S., \& Vercellotti, G.M. (1993). Vitamin E, LDL, and endothelium. Brief oral vitamin supplementation prevents oxidized LDL-mediated vascular injury in vitro. Arterioscler Thromb, 13(12), 1779-1789.

Bethin, K.E., Vogt, S.K., Muglia, L.J. (2000) Interleukin-6 is an essential, corticotropin-releasing hormoneindependent stimulator of the adrenal axis during immune system activation. Proc Natl Acad Sci USA 97(16), 9317-22.

Bianchi, V.E. (2018). The anti-inflammatory effects of testosterone. Journal of the Endocrine Society, 3(1), 91107.

Biswajit, R. (2013). Zinc and male reproduction in domestic animals: A review. Indian Journal of Animal Nutrition, 30(4), 339-350.

Bosco, C., Colli, R., Bonomi, R., von Duvillard, S.P., Viru, A. (2000). Monitoring strength training: neuromuscular and hormonal profile. Med Sci Sports Exerc, 32(1), 2028.

Brownlee, K. K., Moore, A. W., \& Hackney, A. C. (2005). Relationship between circulating cortisol and testosterone: influence of physical exercise. J Sports Sci Med, 4(1),76-83.

Chen, S., Jiang, H., Wu, X., \& Fang, Jet. (2016). Therapeutic Effects of Quercetin on Inflammation, Obesity, and Type 2 Diabetes. Mediators Inflamm, 2016, 9340637.

Coffey, V.G., Zhong, Z., Shield, A., Canny, B.J., Chibalin, A.V., Zierath, J.R., \& Hawley, J.A. (2006) Early signaling responses to divergent exercise stimuli in skeletal muscle from well-trained humans. The FASEB Journal, 20, 190-192.

Crewther, B., Cronin, J., Keogh, J., \& Cook, C. (2008). The salivary testosterone and cortisol response to three loading schemes. J Strength Cond Res, 22(1), 250-255.

Crewther, B., Keogh, J., Cronin, J., \& Cook, C. (2006). 
Possible stimuli for strength and power adaptation: acute hormonal responses. Sports Med, 36(3), 215-238.

Crewther, B.T., Carruthers, J., Kilduff, L.P., Sanctuary, C.E., \& Cook, C.J. (2016). Temporal associations between individual changes in hormones, training motivation and physical performance in elite and non-elite trained men. Biology of Sport, 33(3), 215-221.

Csonka, C., Sárközy, M., Pipicz, M., Dux, L., \& Csont. T. (2016). Modulation of hypercholesterolemia-induced oxidative/nitrative stress in the heart. Oxidative Medicine and Cellular Longevity, 2016.

Culty, M., Luo, L., Yao, Z.X., Chen, H., Papadopoulos, V., \& Zirkin, B.R. (2002). Cholesterol transport, peripheral benzodiazepine receptor, and steroidogenesis in aging Leydig cells. J Androl, 23(3), 439-447.

Dachana, K., Rajiv, J., Indrani, D. \& Prakash, J. (2010). Effect of dried moringa (moringa oleifera lam) leaves on rheological, microstructural, nutritional, textural and organoleptic characteristics of cookies. J Food Qual, 33, 660-677.

Das, N., Ganguli, D., \& Dey, S. (2015). Moringa oleifera Lam. seed extract prevents fat diet induced oxidative stress in mice and protects liver cell-nuclei from hydroxyl radical mediated damage. Indian J Exp Biol, 53(12):794802.

Diemer, T., Allen, J.A., Hales, K.H., \& Hales, D.B. (2003). Reactive oxygen disrupts mitochondria in MA-10 tumor Leydig cells and inhibits steroidogenic acute regulatory (StAR) protein and steroidogenesis. Endocrinology,144(7), 2882-2891.

Eacker, S.M., Agrawal, N., Qian K., Dichek, H.L., Gong, E.Y., Lee, K., Braun, R.E. (2008). Hormonal regulation of testicular steroid and cholesterol homeostasis. Molecular Endocrinology, 22(3), 623-635.

Eid, H.M., Martineau, L.C., Saleem, A., Muhammad, A., Vallerand, D., Benhaddou-Andaloussi, A., Nistor, L., Afshar, A., Arnason, J.T., \& Haddad, P.S. (2010). Stimulation of AMP-activated protein kinase and enhancement of basal glucose uptake in muscle cells by quercetin and quercetin glycosides, active principles of the antidiabetic medicinal plant Vaccinium vitis-idaea. Mol Nutr Food Res, 54(7), 991-1003.

Eid, H.M., Nachar, A., Thong, F., Sweeney, G., \& Haddad, P.S. (2015). The molecular basis of the antidiabetic action of quercetin in cultured skeletal muscle cells and hepatocytes. Pharmacogn Mag, 11(41), 74-81.

Emanuel, A. S., McCully, S. N., Gallagher, K. M., \& Updegraff, J. A. (2012). Theory of planned behavior explains gender difference in fruit and vegetable consumption. Appetite, 59(3), 693-697.

Fallah, A., Mohammad-Hasani, A., Colagar, A. H. (2018). Zinc is an essential element for male fertility: A review of zn roles in men's health, germination, sperm quality, and fertilization. J Reprod Infertil, 19(2), 69-81.

Farrelly, D., Owens, R., Elliott, H., Walden, H., \& Wetherell, M. (2015). The effects of being in a "new relationship" on levels of testosterone in men. Evol Psychol, 13(1),

\section{0-261.}

Febbraio, M.A., Hiscock, N., Sacchetti, M., Fischer, C.P., \& Pedersen, B.K. (2004) Interleukin-6 is a novel factor mediating glucose homeostasis during skeletal muscle contraction. Diabetes 53(7), 1643-8.

Feldman, H.A., Longcope, C., Derby, C.A., Johannes, C.B., Araujo, A.B., Coviello, A.D., Bremner, W.J., \& McKinlay, J.B. (2002). Age trends in the level of serum testosterone and other hormones in middle-aged men: longitudinal results from the Massachusetts male aging study. J Clin Endocrinol Metab, 87(2), 589-598.

Fuhrman, B. \& Aviram, M. (2001). Flavonoids protect LDL from oxidation and attenuate atherosclerosis. Curr Opin Lipidol, 12(1), 41-48.

Ganatra, T. H., Umang, H. J., Payal, N. B., Tusharbindu, R. D., \& Pravin, R. T. (2012). A panoramic view on pharmacognostic, pharmacological, nutritional, therapeutic and prophylactic values of Moringa oleifera. International Research Journal of Pharmacy, 3(6), 1-7.

Gar, C., Rottenkolber, M., Haenelt, M., Potzel, A.L., KernMatschilles, S., Then, C., Seissler, J., Bidlingmaier, M., \& Lechner, A. (2020). Altered metabolic and hormonal responses to moderate exercise in overweight/obesity. Metabolism, 107.

Gargaglioni, L. H., \& Marques, D. A. (2020). Let's talk about sex in the context of COVID-19. J Appl Physiol, 128(6), 1533-1538.

Geisler, S., Aussieker, T., Paldauf, S., Scholz, S., Kurz, M., Jungs, S., Rissmeyer, M., Achtzehn, S., \& Zinner C. (2019). Salivary testosterone and cortisol concentrations after two different resistance training exercises. J Sports Med Phys Fitness, 59(6), 1030-1035.

Giagulli, V.A., Guastamacchia, E., Magrone, T., Jirillo, E., Lisco, G., De Pergola, G., \& Triggiani V. (2021). Worse progression of COVID-19 in men: Is testosterone a key factor? Andrology, 9(1), 53-64.

Gleicher, S., Daugherty, M., Ferry, E., \& Byler, T. (2020). Looking beyond hypogonadism: Association between low testosterone and metabolic syndrome in men $20-$ 59 years. Int Urol Nephrol, 52(12), 2237-2244.

Glover-Amengor, M., Aryeetey, R., Afari, E. and Nyarko, A. (2017), Micronutrient composition and acceptability of Moringa oleifera leaf-fortified dishes by children in Ada-East district, Ghana. Food Sci Nutr, 5, 317-323.

Gopalakrishnan, L. et al. (2016). Moringa oleifera: A review on nutritive importance and its medicinal application. Food Sci Hum Well, 5(2), 49-56.

Goswami, S. K., Inamdar, M. N., Dethe, S. M., Gururaj, G. M., Jamwal, R., Bhaskar, A., Mundkinajeddu, D., and Agarwal, A. (2016) Erectogenic and Aphrodisiac Property of Moringa oleifera: Involvement of soluble epoxide hydrolase enzyme. Phytother Res, 30, 11191127.

Gupta, R., Mathur, M., Bajaj, V.K., Katariya, P., Yadav, S., Kamal, R., \& Gupta, R.S. (2012). Evaluation of antidiabetic and antioxidant activity of Moringa 
oleifera in experimental diabetes. J Diabetes, 4(2), 164171.

Hackney, A. C., \& Walz, E. A. (2013). Hormonal adaptation and the stress of exercise training: the role of glucocorticoids. Trends Sport Sci, 20(4), 165-171.

Han, B., Yu, Y. Q., Yang, Q. L., Shen, C. Y., \& Wang, X. J. (2017). Kaempferol induces autophagic cell death of hepatocellular carcinoma cells via activating AMPK signaling. Oncotarget, 8(49), 86227-86239.

Harman, M., Metter, J., Tobin, J., Pearson, J., Blackman, M. (2001). Longitudinal effects of aging on serum total and free testosterone levels in healthy men. The J Clin Endocrinol Metab, 86(2), 724-731.

Hoffmann, C. \& Weigert, C. (2017). Skeletal Muscle as an Endocrine Organ: The Role of Myokines in Exercise Adaptations. Cold Spring Harb Perspect Med, 7(11), a029793.

Hollman, P.C., van Trijp, J.M., Mengelers, M.J., de Vries, J.H., \& Katan, M.B. (1997). Bioavailability of the dietary antioxidant flavonol quercetin in man. Cancer Lett, 114(1-2), 139-140.

Idohou-Dossou, N., Diouf, A. Gueye, A.L., Guiro, A.T., \& Wade, S. (2011). Impact of daily consumption of Moringa (Moringa oleifera) dry leaf powder on iron status of Senegalese lactating women. African Journal of Food, Agriculture, Nutrition and Development, 11(4), 4985-4999.

Ieronymaki, E., Ieronymaki, E., Daskalaki, M.G., Lyroni, K., \& Tsatsanis, C. (2019). Insulin signaling and insulin resistance facilitate trained immunity in macrophages through metabolic and epigenetic changes. Frontiers in Immunology, 10, 1330.

Jalali, G.R., Roozbeh, J., Mohammadzadeh, A., Sharifian, M., Sagheb, M.M., Hamidian Jahromi, A., Shabani, S., Ghaffarpasand, F., \& Afshariani, R. (2010). Impact of oral zinc therapy on the level of sex hormones in male patients on hemodialysis. Ren Fail, 32(4), 417-419.

Juan, C.A. (2019). Acute weight training-induced testosterone responses of trained males across age groups and diets: A pilot study. J Eurasia Sports Sci Med, 1(2), 79-93.

Karthikesan, K., Pari, L., \& Menon, V.P. (2010). Antihyperlipidemic effect of chlorogenic acid and tetrahydrocurcumin in rats subjected to diabetogenic agents. Chem Biol Interact, 188(3), 643-50.

Kelly, D. M., Akhtar, S., Sellers, D. J., Muraleedharan, V., Channer, K. S., \& Jones, T. H. (2016). Testosterone differentially regulates targets of lipid and glucose metabolism in liver, muscle and adipose tissues of the testicular feminised mouse. Endocrine, 54(2), 504-515.

Kelly, D.M., \& Jones, T.H. (2013). Testosterone: A metabolic hormone in health and disease. J Endocrinol, 217(3), R25-45.

Kraemer, W.J., Häkkinen, K., Newton, R.U., McCormick, M., Nindl, B.C., Volek, J.S., Gotshalk, L.A., Fleck, S.J., Campbell, W.W., Gordon, S.E., Farrell, P.A., \& Evans, W.J. (1998). Acute hormonal responses to heavy resistance exercise in younger and older men. Eur J Appl Phvsiol, 77, 206-211.

Kraemer, W.J., Ratamess, N. A., Hymer, W.C., Nindl, B.C., \& Fragala, M.S. (2020). Growth hormone(s), testosterone, insulin-like growth factors, and cortisol: Roles and integration for cellular development and growth with exercise. Frontiers in Endocrinology, 11, 33.

Kumagai, H., Zempo-Miyaki, A., Yoshikawa, T., Tsujimoto, T., Tanaka, K., \& Maeda, S. (2016). Increased physical activity has a greater effect than reduced energy intake on lifestyle modification-induced increases in testosterone. J Clin Biochem Nutr, 58(1), 84-89.

Kumar, N., Verma, R.P., Singh, L.P., Varshney, V.P., \& Dass R.S. (2006). Effect of different levels and sources of zinc supplementation on quantitative and qualitative semen attributes and serum testosterone level in crossbred cattle (Bos indicus $\times$ Bos taurus) bulls. Reprod Nutr Dev, 46, 663-675.

Kumari, D.J. (2010). Hypoglycaemic effect of Moringa oleifera and Azadirachta indica in type 2 diabetes mellitus. Bioscan 5, 211-214.

Lako, J., Trenerry, V.C., Wahlqvist, M., Wattanapenpaiboon, N., Sotheeswaran, S., \& Premier, R.. (2007). Phytochemical flavonols, carotenoids and the antioxidant properties of a wide selection of Fijian fruit, vegetables and other readily available foods. Food Chem, 101(4), 1727-1741.

Leone, A., Spada, A., Battezzati, A., Schiraldi, A., Aristil, J., \& Bertoli, S. (2015). Cultivation, Genetic Ethnopharmacology, Phytochemistry, and Pharmacology of Moringa oleifera Leaves: An Overview. Int J Mol Sci, 16(6), 12791-835.

Leproult, R., \& Van Cauter, E. (2011). Effect of 1 week of sleep restriction on testosterone levels in young healthy men. JAMA, 305(21), 2173-2174.

Loke, W.M. et al. (2008). Quercetin and its in vivo metabolites inhibit neutrophil-mediated low-density lipoprotein oxidation. J Agric Food Chem, 56(10), 36093615.

Lopes, J., Araujo, S.S., Estevam, C.S., Lima, C.A., Carvalho, C.R.O., Lima, F.B., Marcal, A.C. (2017). Molecular Mechanisms of Muscle Glucose Uptake in Response to Resistance Exercise: A Review. JEPonline, 20(4), 200211.

Lunenfeld, B., Arver, S., Moncada, I., Rees, D. A., \& Schulte, H. M. (2012). How to help the aging male? Current approaches to hypogonadism in primary care. Aging Male, 15(4), 187-197.

Majumdar, P., \& Srividhya Jr., S. (2010). Monitoring training load in Indian male swimmers. Int J Exerc Sci, 3(3), 102-107.

Martínez-Martos, J.M., Arrazola, M., Mayas, M.D., CarreraGonzález, M.P., García, M.J., Ramírez-Expósito, M.J. (2011). Diet-induced hypercholesterolemia impaired testicular steroidogenesis in mice through the reninangiotensin system. Gen Comp Endocrinol 173(1), 15-9.

Maso, F., Lac, G., Filaire, E., Michaux, O., Robert, A. (2004). 
Salivary testosterone and cortisol in rugby players: correlation with psychological overtraining items. $\mathrm{Br} \mathrm{J}$ Sports Med, 38(3), 260-3.

Mbikay, M. (2012). Therapeutic potential of moringa oleifera leaves in chronic hyperglycemia and dyslipidemia: A review. Frontiers in Pharmacology, 3, 24.

McMurray, R.G. \& Hackney, A.C. (2005). Interactions of metabolic hormones, adipose tissue and exercise. Sports Med, 35, 393-412.

Miller, W.L., \& Bose, H.S. (2011). Early steps in steroidogenesis: intracellular cholesterol trafficking. $J$ Lipid Res, 52(12), 2111-2135.

Mohamed, M.A. (2019). Molecular effects of Moringa leaf extract on insulin resistance and reproductive function in hyperinsulinemic male rats. Journal of Diabetes and Metabolic Disorders, 18, 487-494.

Mohamed, M.S., Moulin, T.C. \& Schiöth, H.B. (2020). Sex differences in COVID-19: The role of androgens in disease severity and progression. Endocrine, 71(1), 3-8.

Mulligan, T., Frick, M.F., Zuraw, Q.C., Stemhagen, A., \& McWhirter, C. (2006). Prevalence of hypogonadism in males aged at least 45 years: the HIM study. Int J Clin Pract, 60(7), 762-769.

Munawar, M. et al. (2019). Depleted levels of testosterone instigated by statins in patients with hyperlipidemia can be avoided if substituted by moringa leaves. International Journal of Biology, Pharmacy, and Allied Sciences, 8(10), 1908-1915.

Muraleedharan, V., \& Jones, T.H. (2010). Testosterone and the metabolic syndrome. Ther Adv Endocrinol Metab, 1(5), 207-223.

Nagata, C., Takatsuka, N., Shimizu, H., Hayashi, H., Akamatsu, T., \& Murase, K. (2001). Effect of soymilk consumption on serum estrogen and androgen concentrations in Japanese men. Cancer Epidemiol Biomarkers Prev, 10(3), 179-184.

Nambiar, V.S., Guin, P., Parnami, S. \& Daniel, M. (2010). Impact of antioxidants from drumstick leaves on the lipid profile of hyperlipidemics. Journal of Herbal Medicine and Toxicology 4,165-172.

Ndong, M., Uehara, M., Katsumata, S., \& Suzuki, K. (2007). Effects of oral administration of Moringa oleifera on glucose tolerance in Goto-Kakizaki and Wistar rats. $J$ Clin Biochem Nutr, 40, 229-233.

Ogunsola, O.A., Owolabi, J.O., Fabiyi, O.S., Nwobi, N.L., Faluyi, B., \& Akinbola, A.S. (2017). Moringa plant parts consumption had effects on reproductive functions in male and female rat models. Journal of Dental and Medical Sciences, 16, 82-86.

Olayaki, L.A., Irekpita, J.E., Yakubu, M.T., Ojo, O.O. (2015). Methanolic extract of Moringa oleifera leaves improves glucose tolerance, glycogen synthesis and lipid metabolism in alloxan-induced diabetic rats. J Basic Clin Physiol Pharmacol, 26(6), 585-593.

Omi, N., Shiba, H., Nishimura, E., Tsukamoto, S., MarukiUchida, H., Oda, M., \& Morita, M. (2019) Effects of enzymatically modified isoquercitrin in supplementary protein powder on athlete body composition: a randomized, placebo-controlled, double-blind trial. $J$ Int Soc Sports Nutr 16(1), 39.

Ong, K.W., Hsu, A., Tan, B.K. (2013). Anti-diabetic and antilipidemic effects of chlorogenic acid are mediated by AMPK activation. Biochem Pharmacol, 85(9), 13411351.

Paula, P.C., Oliveira, J.T., Sousa, D.O., Alves, B.G.T., Carvalho, A.F.U., Franco, O.L., \& Vasconcelos, I.M. (2017). Insulinlike plant proteins as potential innovative drugs to treat diabetes. The Moringa oleifera case study. N Biotechnol, 39, 99-109.

Pitteloud, N. (2005). Relationship between testosterone levels, insulin sensitivity, and mitochondrial function in men. Diabetes Care, 28(7), 1636-1642.

Pivonello R., Menafra D, Riccio, E., Garifalos, F., Mazzella, M., de Angelis, C., \& Colao, A. (2019). metabolic disorders and male hypogonadotropic hypogonadism. Front Endocrinol, 10, 345.

Pozzilli, P. \& Lenzi, A. (2020). Testosterone, a key hormone in the context of COVID-19 pandemic. Metabolism, 108, 154252.

Prabsattroo, T., Wattanathorn, J., Iamsaard, S., Somsapt, P., Sritragool, O., Thukhummee, W., \& Muchimapura, S. (2015). Moringa oleifera extract enhances sexual performance in stressed rats. Journal of Zhejiang University. Science. B, 16(3), 179-190.

Proschinger, S. \& Freese, J. (2019). Neuroimmunological and neuroenergetic aspects in exercise-induced fatigue. Exerc Immunol Rev 25, 8-19.

Randle, P.J., Garland, P.B., Hales, C.N. \& Newsholme, E.A. (1963). The glucose fatty-acid cycle: Its role in insulin sensitivity and the metabolic disturbances of diabetes mellitus. Lancet, 1, 785-789.

Rao, P.M., Kelly, D.M., Jones, T.H. (2013). Testosterone and insulin resistance in the metabolic syndrome and T2DM in men. Nat Rev Endocrinol, 9(8), 479-493.

Rasmussen, J. J., Selmer, C., Østergren, P. B., Pedersen, K. B., Schou, M., Gustafsson, F., Faber, J., Juul, A., \& Kistorp, C. (2016). Former abusers of anabolic androgenic steroids exhibit decreased testosterone levels and hypogonadal symptoms years after cessation: a casecontrol study. PloS One, 11(8), e0161208.

Ratamess, N.A., Kraemer, W.J., Volek, J.S., Maresh, C.M., Vanheest, J.L., Sharman, M.J., Rubin, M.R., French, D.N., Vescovi, J.D., Silvestre, R., Hatfield, D.L., Fleck, S.J., Deschenes, M.R. (2005). Effects of heavy resistance exercise volume on post-exercise androgen receptor. $J$ Steroid Biochem Molec, 93, 35-42.

Riggio, O., Ariosto, F., Merli, M., Caschera, M., Zullo, A., Balducci, G., Ziparo, V., Pedretti, G., Fiaccadori, F., Bottari, E., et al. (1991). Short-term oral zinc supplementation does not improve chronic hepatic encephalopathy. Results of a double-blind crossover trial. Dig Dis Sci, 36(9), 1204-1208.

Roelfsema, F., Yang, R.J., Liu, P.Y., Takahashi, P.Y., \& 
Veldhuis, J.D. (2018). Feedback on LH in TestosteroneClamped Men Depends on the Mode of Testosterone Administration and Body Composition. Journal of the Endocrine Society, 3(1), 235-249.

Sarkola, T., Eriksson, C.J. (2003). Testosterone increases in men after a low dose of alcohol. Alcohol Clin Exp Res, 27(4), 682-5.

Sattler, F., He, J., Chukwuneke, J., Kim, H., Stewart, Y., Colletti, P., Yarasheski, K.E., \& Buchanan, T.A. (2014). Testosterone supplementation improves carbohydrate and lipid metabolism in some older men with abdominal obesity. J Gerontol Geriatr Res, 3(3), 1000159.

Saxe, G. A., Major, J. M., Westerberg, L., Khandrika, S., \& Downs, T. M. (2008). Biological mediators of effect of diet and stress reduction on prostate cancer. Integrative Cancer Therapies, 7(3), 130-138.

Sellami M, Dhahbi W, Hayes LD, Kuvacic G, Milic M, Padulo J. (2018). The effect of acute and chronic exercise on steroid hormone fluctuations in young and middleaged men. Steroids, 132, 18-24.

Steensberg, A., Fischer, C.P., Keller, C., Møller, K., Pedersen, B.K. (2003) IL-6 enhances plasma IL-1ra, IL-10, and cortisol in humans. Am J Physiol Endocrinol Metab 285(2), E433-7.

Stohs, S. J., \& Hartman, M. J. (2015). Review of the Safety and Efficacy of Moringa oleifera. Phytotherapy Research, 29(6), 796-804.

Suarni, N.M., Oka, I.G.L., Mahardika, I.G., Suyadnya, I.P. (2019). Testosterone level and mating capability of male rabbit fed commercial feed substituted with moringa oleifera leaf meal. IOP Conference Series, $347(1)$.

Syarifuddin, N.A., Toleng, A.L., Rahardja, D.P., Ismartoyo, I., \& Yusuf, M. (2017). Improving libido and sperm quality of Bali bulls by supplementation of moringa oleifera leaves. Media Peternakan, 40(2), 88-93.

Tanaka, M., Nakaya, S., Kumai, T., Watanabe, M., Matsumoto, N., Kobayashi, S. (2001). Impaired testicular function in rats with diet-induced hypercholesterolemia and/or streptozotocin-induced diabetes mellitus. Endocr Res 27(1-2), 109-17.

Tang, Y., Choi, E.J., Han, W.C., Oh, M., Kim, J., Hwang, J.Y., Park, P.J., Moon, S.H., Kim, Y.S., \& Kim, E.K. (2017). moringa oleifera from cambodia ameliorates oxidative stress, hyperglycemia, and kidney dysfunction in type 2 diabetic mice. J Med Food, 20(5), 502-510.

Thirumalai, A., Rubinow, K.B., \& Page, S.T. (2015). An update on testosterone, HDL and cardiovascular risk in men. Clinical Lipidology, 10(3), 251-258.

Tshingani, K., Donnen, P., Mukumbi, H., Duez, P., \& Dramaix-Wilmet, M. (2017). Impact of Moringa oleifera lam. Leaf powder supplementation versus nutritional counseling on the body mass index and immune response of HIV patients on antiretroviral therapy: a single-blind randomized control trial. BMC Complement Altern Med, 22, 17(1), 420.
Vaamonde, D., Da Silva-Grigoletto, M.E., García-Manso, J.M., Barrera, N., \& Vaamonde-Lemos, R. (2012). Physically active men show better semen parameters and hormone values than sedentary men. Eur J Appl Physiol, 112(9), 3267-73.

Van Anders, S.M. \& Watson, N.V. (2006). Relationship status and testosterone in North American heterosexual and non-heterosexual men and women: Cross-sectional and longitudinal data. Psychoneuroendocrinology, 31(6), 715-723.

Vargas, N.T. \& Marino, F. (2014) A neuroinflammatory model for acute fatigue during exercise. Sports Med, 44(11), 1479-1487.

Vargas-Sánchez, K., Garay-Jaramillo, E., \& González-Reyes, R. E. (2019). Effects of Moringa oleifera on Glycaemia and Insulin Levels: A Review of Animal and Human Studies. Nutrients, 11(12), 2907.

Villaruel-López, A., López-de la Mora, D., Vasquez-Paulino, O., Puebla-Mora, A., Torres-vitela, M., Guerrero-Quiroz, L., Nuño, K. (2018). Effect of Moringa oleifera consumption on diabetic rats. BMC Complement Altern Med, 18, 127.

Wambier, C.G. \& Goren, A. (2020). Severe acute respiratory syndrome coronavirus 2 (SARS-CoV-2) infection is likely to be androgen mediated. J Am Acad Dermatol, 83(1), 308-309.

Wang, W., Yang, X., Liang, J., Liao, M., Zhang, H., Qin, X., Mo, L., Lv, W., \& Mo, Z. (2013). Cigarette smoking has a positive and independent effect on testosterone levels. Hormones (Athens), 12(4), 567-77.

Waterman, C., Rojas-Silva, P., Tumer, T.B., Kuhn, P., Richard, A.J., Wicks, S., Stephens, J.M., Wang, Z., Mynatt, R., Cefalu, W., \& Raskin, I. (2015). Isothiocyanate-rich Moringa oleifera extract reduces weight gain, insulin resistance, and hepatic gluconeogenesis in mice. Mol Nutr Food Res, 59(6), 1013-1024.

Wong, T., Harber, V. (2006). Lower excess postexercise oxygen consumption and altered growth hormone and cortisol responses to exercise in obese men. J Clin Endocrinol Metab, 91(2), 678-86.

Xiao, J., Huang, W.H., Peng, J.B., Tan, Z.R., Ou-Yang, D.S., Hu, D.L., Zhang, W., \& Chen, Y. (2014). Quercetin significantly inhibits the metabolism of caffeine, a substrate of cytochrome P450 1A2 unrelated to CYP1A2*1C $(-2964 \mathrm{G}>\mathrm{A})$ and $* 1 \mathrm{~F} \quad(734 \mathrm{C}>\mathrm{A})$ gene polymorphisms. Biomed Res Int, 2014, 405071.

Xu, Y.B., Chen, G.L., Guo, M.Q. (2019). Antioxidant and antiinflammatory activities of the crude extracts of moringa oleifera from Kenya and their correlations with flavonoids. Antioxidants (Basel), 8(8), 296.

Yang, J., Zhang, X., Liu, Z., Yuan, Z., Song, Y., Shao, S., Zhou, X., Yan, H., Guan, Q., Gao, L., Zhang, H., Zhao, J. (2016). High-cholesterol diet disrupts the levels of hormones derived from anterior pituitary basophilic cells. $J$ Neuroendocrinol, 28(3), 12369.

Yassa, H.D. \& Tohamy, A.F. (2014). Extract of Moringa oleifera leaves ameliorates streptozotocin-induced 
Diabetes mellitus in adult rats. Acta Histochem, 116(5), 844-854.

Yu, C., Jiang, F., Zhang, M., Luo, D., Shao, S., Zhao, J., Gao, L., Zuo, C., \& Guan, Q. (2019). HC diet inhibited testosterone synthesis by activating endoplasmic reticulum stress in testicular Leydig cells. J Cell Mol Med 23(5), 3140-3150.

Zade, V., Dabhadkar, D., Thakare, V., Pare, S. (2013). Evaluation of potential aphrodisiac activity of Moringa oleifera seed in male Albino rats. International Journal of Pharmacy and Pharmaceutical Sciences, 5, 683-689.

Zhao, J.L., Zhao, Y.Y., Zhu, W.J. (2017). A high-fat, highprotein diet attenuates the negative impact of caseininduced chronic inflammation on testicular steroidogenesis and sperm parameters in adult mice. Gen Comp Endocrinol 252, 48-59. 